\title{
Anti-Oxidant, Anti-Inflammatory and Anti-Allergic Activities of Luteolin
}

Author

Affiliation
Günter Seelinger ${ }^{1}$, Irmgard Merfort ${ }^{2}$, Christoph M. Schempp ${ }^{3}$

Medical Services Dr. Seelinger, Berlin, Germany

Institute of Pharmaceutical Sciences, Department of Pharmaceutical Biology and Biotechnology, University of Freiburg,

Freiburg, Germany

Competence Center Skintegral $^{\circledR}$, Department of Dermatology, University Medical Center Freiburg, Freiburg, Germany
Key words

- luteolin

- flavonoids

- Reseda luteola L.

- Resedaceae

- free radical scavengers

received June 18, 2008

revised July 18,2008

accepted July 25, 2008

Bibliography

DOI $10.1055 / \mathrm{s}-0028-1088314$

Planta Med 2008; 74: 1667-

1677

(c) Georg Thieme Verlag KG

Stuttgart · New York

Published online October 20,

2008

ISSN 0032-0943

Correspondence

Prof. Dr. med. Christoph M.

\section{Schempp}

Competence Center Skintegral ${ }^{\circledR}$ Department of Dermatology

University Medical Center

Freiburg

Hauptstr. 7

79102 Freiburg

Germany

Tel.: +49-761-270-6701

Fax: +49-761-270-6829

christoph.schempp@uniklinik-

freiburg.de

\section{Abstract}

$\nabla$

Luteolin is a flavone which occurs in medicinal plants as well as in some vegetables and spices. It is a natural anti-oxidant with less pro-oxidant potential than the flavonol quercetin, the best studied flavonoid, but apparently with a better safety profile. It displays excellent radical scavenging and cytoprotective properties, especially when tested in complex biological systems where it can interact with other anti-oxidants like vitamins. Luteolin displays specific anti-inflammatory effects at micromolar concentrations which are only partly explained by its anti-oxidant capacities. The anti-inflammatory activity includes activation of anti-oxidative enzymes, suppression of the NFKB pathway and inhibition of pro-inflammatory substances. In vivo, luteolin reduced increased vascular permeability and was effective in animal models of inflammation after parenteral and oral application. Although luteolin is only a minor component in our nutrition (less than $1 \mathrm{mg} /$ day) epidemiological studies indicate that it has the potential to protect from diseases associated with inflammatory processes such as cardiovascular disease. Luteolin often occurs in the form of glycosides in plants, but these are cleaved and the aglycones are conjugated and metabolized after nutritional uptake which has to be considered when evaluating in vitro studies. Some data for oral and topical bioavailability exist, but more quantitative research in this field is needed to evaluate the physiological and therapeutical potential of luteolin.

\section{Introduction \\ $\nabla$}

Luteolin is a flavone contained in many medical plants and in vegetables. However, concentrations are generally low compared to some of the flavonols like quercetin or kaempferol. Consider-

\begin{tabular}{|c|c|}
\hline \multicolumn{2}{|c|}{$\begin{array}{l}\text { Abbreviations } \\
\nabla\end{array}$} \\
\hline Akt: & serine/threonin protein kinase B \\
\hline COX-2: & cyclooxygenase-2 \\
\hline CVD: & cardiovascular disease \\
\hline DPPH: & 2,2-diphenyl-1-picrylhydrazyl \\
\hline EAE: & $\begin{array}{l}\text { experimental autoimmune } \\
\text { encephalomyelitis }\end{array}$ \\
\hline EGCG: & epigallocatechin 3-gallate \\
\hline fMLP: & fMetLeuPhe, formyl peptide \\
\hline GSH: & glutathione \\
\hline IFN- $\gamma$ & interferon $\gamma$ \\
\hline $\mathrm{I} \kappa \mathrm{B}:$ & Inhibitor of kappa B \\
\hline IL: & interleukin \\
\hline iNOS: & inducible nitric oxygen synthase \\
\hline IP-10: & inducible nitric oxygen synthase \\
\hline IRF: & interferon regulatory factor \\
\hline LPS: & lipopolysaccharide \\
\hline LysoPAF AcTF: & $\begin{array}{l}\text { 1-lysophospholipide } \\
\text { acetyltransferase }\end{array}$ \\
\hline MAPK: & mitogen-activated protein kinase \\
\hline M-CSF: & $\begin{array}{l}\text { macrophage colony-stimulating } \\
\text { factor }\end{array}$ \\
\hline NFкB: & nuclear factor kappa B \\
\hline 8-OHdG: & 8-hydroxy-2'-deoxyguanosine \\
\hline $\mathrm{PGE}_{2}$ : & prostaglandin $\mathrm{E}_{2}$ \\
\hline PMA: & phorbol myristate acetate \\
\hline ROS: & reactive oxygen species \\
\hline TEAC: & $\begin{array}{l}\text { trolox equivalent anti-oxidant } \\
\text { capacity }\end{array}$ \\
\hline TNF- & tumor necrosis factor- $\alpha$ \\
\hline
\end{tabular}

Abbreviations

Akt: $\quad$ serine/threonin protein kinase $B$

COX-2: $\quad$ cyclooxygenase-2

CVD:

cardiovascular disease experimental autoimmune encephalomyelitis metleuPhe, glutathione interferon $\gamma$ interleukin inducible nitric oxygen synthase interferon regulatory factor tumor necrosis factor- $\alpha$

able concentrations are found in some spices like thyme, parsley, sage, in wild carrots, artichokes and in peanut hulls. Celery, spinach, some varieties of peppers and lettuce are our major nutritional luteolin sources [1]. While luteolin is only a minor flavonoid component in food, high 
amounts can be isolated from peanut hulls and Reseda luteola $\mathrm{L}$. that has been used as a dyeing plant due to its high luteolin content since ancient times [2].

While quercetin has been studied most intensively among the flavonoids during the last decades, recent research has provided a plethora of anti-oxidant, immunological, anti-carcinogenic, anti-bacterial, cardiovascular and other pharmacological mechanisms which suggest luteolin to be a valuable compound for many medical applications. Meanwhile, it is already advertised and marketed as a food additive. Some epidemiological investigations indeed indicate that luteolin intake may protect from cardiovascular diseases or some cancer species, but prospective clinical studies are widely lacking. The present review gives an account of the pharmacological data for luteolin concerning its anti-oxidant, anti-inflammatory and anti-allergic functions, comparing it to other flavonoids.

When evaluating the effects of flavonoids, their administration form has to be considered as they are often highly metabolized when taken orally [3]. In this paper, "luteolin" generally applies to the aglycone; when glycosides were used, these are specified. The literature search was initiated to the end of February 2008 using "luteolin" as a key-word in the Pubmed database, yielding 1085 results, and in Medline, with 1077 citations. Restriction to title search in Medline gave 163 results, and 192 were obtained from Pubmed under restriction to the toxicology section. Both lists were checked for relevant literature. Additionally, "related articles" proposed by Pubmed for the selected citations were systematically searched. Articles relating to other fields like anti-carcinogenic or metabolic effects were not selected, although sometimes overlapping with anti-oxidant or antiinflammatory effects.

\section{Anti-Oxidant Effects}

$\nabla$

Anti-oxidant properties of a specific substance are complex, and relative efficacies of two substances in different assays can vary. An anti-oxidant action is therefore not characterized by a general "total anti-oxidant coefficient", but by its performance in different test systems [4]. This even applies to simple test assays with a minimal number of agents, since they determine specific characters like "peroxyl radical scavenging capacity" or "ferric ion reducing capacity". Numerous assays exist to determine the anti-oxidant capacity of anti-oxidants not only in a reduced chemical environment, but also in cellular systems or in vivo, where the preventive effect on oxidant-induced damage can be studied [5]. Anti-oxidant mechanisms and structure-activity relationships of flavonoids have been extensively described by Havsteen [6] and Heim et al. [7] in the context of comprehensive review articles. Specific data for the anti-oxidant effects of luteolin exist for a wide range of experimental conditions.

\section{Cell-free systems}

Belyakov et al. [8], using a chemiluminescence method, found flavonoids with two hydroxy groups in the B-ring to strongly inhibit autoxidation of diphenylmethane. Time constants (in $\mathrm{k} / 10^{6}$ $\mathrm{dm}^{3} \mathrm{~mol}^{-1} \mathrm{~s}^{-1}$ ) of the reaction between flavonoids and diphenylmethane peroxy radical illustrate the influence of flavonoid structure on anti-oxidant capacity: luteolin 22, quercetin 21, dihydroquercetin 19 , catechin 7 , kaempferol 1 [8].

Jovanovic et al. [9] determined the redox properties of various flavonoid radicals generated by azide radical-induced one-elec- tron oxidation in aqueous solutions by a pulse radiolysis technique. Main electron-donating system is the B-ring as long as it is substituted with hydroxy groups; the A-ring is not a good electron donator and will scavenge alkyl peroxide radicals only when the B-ring is not substituted. Quercetin was the best electron donator of the flavonoids tested, due to the favourable electron-donating properties of the (flavonol-) 3-hydroxy group in the C-ring which is conjugated to the B-ring through the 2,3double bond.

The conjugation of the A- and B-rings is minimal. All investigated radicals had reduction potentials lower than that of alkyl peroxyl radicals, the parent flavonoids therefore being qualified as chain-breaking anti-oxidants in any oxidation process mediated by these radicals.

Rice-Evans et al. [8] systematically examined a variety of flavonoids for structure-activity relationships in the ABTS/trolox equivalent anti-oxidant capacity (TEAC) assay. Flanonoids with a high TEAC had many hydroxy groups and were characterized by:

1. An ortho-dihydroxy structure in the B-ring; dihydroxy groups in meta-positions, monohydroxylation, and a trihydroxy substitution were less effective.

2. A 2,3-double bond in conjunction with the 4-oxo function of the C-ring.

3. Hydroxy substitutions in positions 3 and 5 (see $\bullet$ Fig. 1 for terminology).

While the first two features apply to luteolin, it lacks a 3-hydroxy substitution. Accordingly, luteolin had a good, but not excellently high anti-oxidant capacity in this test. The TEAC for some flavonoids in aqueous phase were determined [10] as: epicatechin gallate: 4.9 , epigallocatechin gallate (EGCG): 4.8 , quercetin: 4.7, myricetin: 3.1, catechin: 2.4 , rutin: 2.4 , luteolin: 2.1, luteolin 4'-glucoside: 1.7 , naringenin: 1.5 , apigenin: 1.45 , chrysin: 1.4, hesperitin: 1.4, kaempferol: 1.3, luteolin 3',7-diglucoside: 0.8. (see $\bullet$ Fig. 1 for structures, and $\bullet$ Fig. 2 for basic anti-oxidative mechanism of flavonoids).

Metal ions bound to biological structures may function as catalytic centers for multiple radical formation. Flavonoids with 0 di-OH groups in the B ring, like quercetin and luteolin, can chelate with the metal ion and are very effective protectives from oxidative damage. Brown et al. [11] used LDL-oxidation induced by either $\mathrm{Cu}^{2+}$ ions or by haem protein to compare the anti-oxidant capacity of these flavonoids. In the $\mathrm{Cu}^{2+}$ system, chelation was seen with both compounds, but quercetin was more effective, possibly due to its 3-OH moiety which gives additional sites for stable chelation. Luteolin has only the possibility for a further chelate complex between its 5-OH and 4-carbonyl, but which has a lower stability [12]. In the haem protein model, however, luteolin was more effective, probably because its higher lipophilicity allowed for better contact with the LDL or because of its higher stability. It was found that quercetin becomes oxidized during the chelation process, while luteolin reverted to its original form. This may explain the ability of quercetin and other flavonols to redox cycle under certain conditions. Stabilization (or elimination, as in luteolin) of the hydroxy group in position 3 is thought to disrupt this adverse effect.

Romanova et al. [13] investigated the DNA-protective effect of luteolin, quercetin and apigenin. With $\mathrm{H}_{2} \mathrm{O}_{2}$ as oxidizing agent, luteolin was the most effective. At low $\mathrm{Fe}^{2+}$ concentrations, apigenin was more effective, while at higher $\mathrm{Fe}^{2+}$ concentrations (10 $\mathrm{mM})$ luteolin and quercetin were superior; apigenin misses a catechol group and a $3-\mathrm{OH}$ moiety and thus can poorly form chelates. 


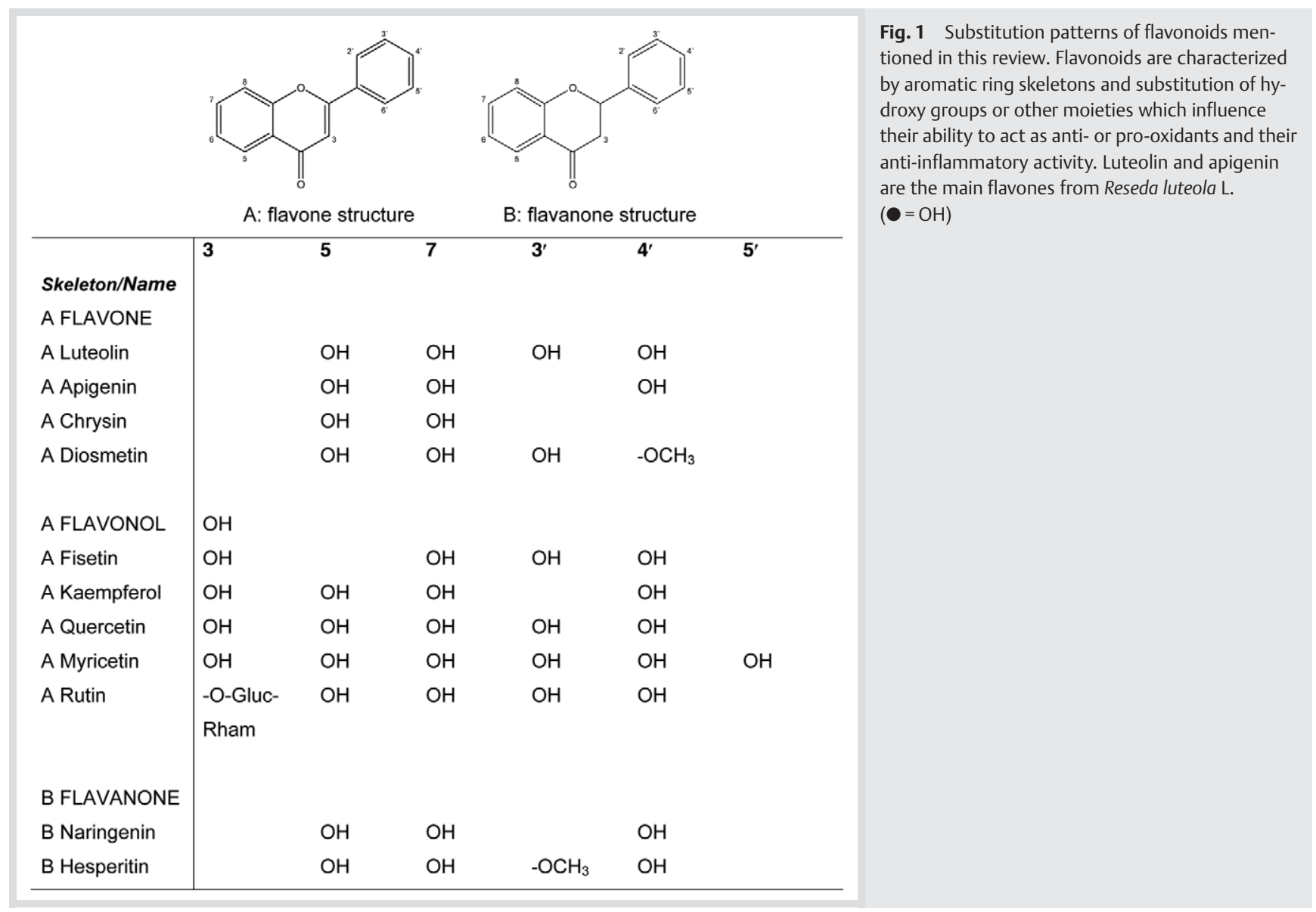

Luteolin was the most effective of 8 flavonoids in a rat liver cell membrane model with ascorbic acid and $\mathrm{Fe}^{2+}$, similar to (-)-epicatechin, but superior to quercetin and, e.g., kaempferol and apigenin. When lipid peroxidation was induced by arachidonic acid, the order was changed, quercetin and luteolin being only moderately active [14]. Luteolin also performed best among 12 flavonoids $(200 \mu \mathrm{M})$ in a lipid peroxidation assay with thiobarbituric acid, using methyl lineolate and Fenton's reagent. The relative efficacy in this assay showed a good correlation with protection from $\gamma$-ray-induced DNA damage after gastric intubation of these flavonoids to mice at $5 \mu \mathrm{mol} / \mathrm{kg}$ [15].

Gal et al. [16] demonstrated, that only 2 of 13 tested flavonoids, luteolin and 3',4',7-trihydroxyflavone, showed "super-anti-oxidant potency" in an assay of $\mathrm{Cu}^{2+}$-induced liposome oxidation when phosphatidylserine was present in the liposomes. For liposomes made of palmitoyllinoleoyl-phosphatidylcholine $(250 \mu \mathrm{M})$ and phosphatidylserine $(25 \mu \mathrm{M})$ the "lag" preceding copper-induced peroxidation ( $5 \mu \mathrm{M}$ copper) was doubled upon addition of 30-130 nM of the "super-active" antioxidants. This was due to replenishment of the anti-oxidant in a tertiary com-

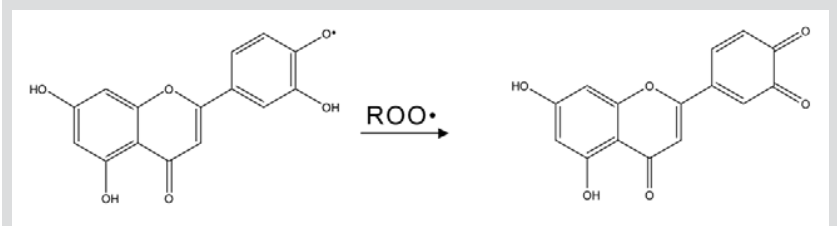

Fig. 2 Anti-oxidant mechanism of flavonoids (from Belyakov, [8]) plex of copper, phosphatidylserine and anti-oxidant. Other flavonoids were either moderately anti-oxidant or pro-oxidative. A change of relative anti-oxidant capacities may also result from interactions between anti-oxidants. Hirano et al. [17] tested 10 flavonoids in two different assays. Epigallocatechin 3-gallate (EGCG) was the most effective radical scavenger in an electron transfer test with 2,2-diphenyl-1-picrylhydrazyl (DPPH), luteolin the least effective. In a second experiment, the mutual antioxidant effect of these flavonoids with $\alpha$-tocopherol was determined in an LDL-peroxidation assay with 2,2'-azobis-(2,4-dimethylvaleronitrile) (AMVN)- $\mathrm{CH}_{3} \mathrm{O}$. The lag time of peroxidation induced by $6 \mathrm{mg} / 100 \mathrm{~mL} \alpha$-tocopherol is shortened by increasing concentrations of the radical initiator, but restored by the flavonoids. In this experiment, luteolin was the most effective of ten flavonoids tested (including quercetin), apigenin being the least effective. Flavonoids act as hydrogen donators for $\alpha$-tocopherol, thereby increasing their potential to delay LDL oxidation.

\section{Cellular systems in vitro}

Cellular systems are, on one hand, more biologically relevant than cell-free assays, because they account for some aspects of uptake, metabolism, and location of the test substances within cells. On the other hand, features specific for the organisms and cells are more involved so that results have to be generalized very carefully; e. g., rat liver has a high potential to cleave flavonoid glycosides, so that these substances appear more effective in relation to their aglycones than in human tissues.

Horváthová et al. [18] used the comet assay to determine the capacities of 4 flavonoids to protect DNA from $\mathrm{H}_{2} \mathrm{O}_{2}$ induced damage in murine leukemia L 1210 cells. At $600 \mu \mathrm{M}$ quercetin had 
the highest protective effect (45\%), followed by luteolin (40\%), while apigenin was only slightly and rutin was not protective. At high, not relevant concentrations of $1200 \mu \mathrm{M}$, apigenin induced single-strand breaks. In human myelogenous leukemia cells (K562) the results were similar, with luteolin (44\%) and quercetin ( $42 \%$ ) protective at $20-100 \mu \mathrm{M}$, rutin being only marginally effective at concentrations up to $1000 \mu \mathrm{M}$, and apigenin displaying no effect [19].

Horváthová et al. [20] demonstrated DNA-protective free radical scavenging potential of luteolin and quercetin in human HMB 2 melanoma cells. Both flavonoids reduced the damage caused by treatment with $\mathrm{H}_{2} \mathrm{O}_{2}$ in a dose-dependent manner, with $40 \%$ inhibition at $20 \mu \mathrm{M}$ up to $80 \%$ at $100 \mu \mathrm{M}$. When combined with melphalan, a cytostatic substance which displays a variety of toxic side effects at high doses, $20 \mu \mathrm{M}$ luteolin significantly reduced the frequency of chromosomal aberrations, whereas quercetin was less effective.

The comet assay was also used to investigate the effect of flavonoids and vitamin $\mathrm{C}$ on oxidative damage from $100 \mu \mathrm{M} \mathrm{H}_{2} \mathrm{O}_{2}$ in human lymphocytes [21]. Luteolin and quercetin were the most effective protectants, with $\mathrm{ED}_{50}$ concentrations of about $50 \mu \mathrm{M}$. At the high concentration of $279 \mu \mathrm{M}$, luteolin suppressed DNA damage almost completely by $91 \%$. Apigenin and rutin or other flavone glycosides were more than 10 times less protective. Vitamin $C$ was less effective than most of the flavonoids, but its effect was additive in combinations.

Luteolin and apigenin were isolated along with many other substances from the Indonesian traditional medicinal plant Guazuma ulmifolia [22]. Luteolin was among the strongest antioxidant compounds in the DPPH assay, while apigenin was ineffective. The authors find a good correlation of anti-oxidative and protective properties of different plant substances in the assays used. Incubation of H4IIE cells for $1 \mathrm{~h}$ with $50 \mu \mathrm{M}$ luteolin reduced $\mathrm{H}_{2} \mathrm{O}_{2}$-induced DNA breakage in the comet assay by 70 $80 \%$. At $100 \mu \mathrm{M}$, the effect of luteolin and kaempferol changed from protective to cytotoxic. The question arises whether this has any relevance, as these high levels of luteolin will never been reached in vivo (see also Section Bioavalibility).

The effect of artichoke extract and some of its flavonoid constituents on reactive oxygen species was investigated in human leukocytes [23]. Three different agents were used to exhibit oxidative stress on the cells in vitro: $\mathrm{H}_{2} \mathrm{O}_{2}$, phorbol myristate acetate (PMA), and formyl peptide (fMLP). $\mathrm{H}_{2} \mathrm{O}_{2}$ is a key compound in free radical metabolism since it can be transformed into other dangerous reactive oxygen species (ROS) in the cell [24]. PMA acts as a tumor promoter and AMLP is a chemotactic peptide released from bacteria during infections. Both stimulate ROS generation by different mechanisms. Artichoke extract and its constituents, caffeic acid, chlorogenic acid, luteolin and luteolin 7glucoside, all showed a concentration-dependent inhibitory activity in the above models [23].

In rat hepatocytes incubated in $1 \mathrm{mM}$ tert-butyl hydroperoxide malondialdehyde production was significantly reduced by flavonoids in concentrations from 5 to $100 \mu \mathrm{M}$, in the order of effectiveness luteolin $=$ fisetin $=$ quercetin $>$ hesperitin $>$ naringenin $>$ apigenin. In contrast to cell-free assays, some glycosides were similarly effective compared to the aglycones, probably due to the high glucosidase activity in rat liver [25].

Wolfe et al. [26] used HepG2 human hepatocarcinoma cells with incorporated dichlorofluorescin which is easily oxidized to a fluorescent derivative. ABAP [2,2'-azobis(2-amidinopropane) dihydrochloride] was used to generate peroxyl radicals. Selected phytochemicals and fruits were used to test their anti-oxidant potential. Luteolin was active but inferior to quercetin, kaempferol, EGCG and myricetin in this test.

Harris et al. [27] hypothesized that differences in anti-oxidant activity between the structurally similar flavones, luteolin and chrysin (missing B-ring hydroxylation), would differentially affect inflammation-associated cyclooxygenase-2 (COX-2) expression and prostaglandin $\mathrm{E}_{2}\left(\mathrm{PGE}_{2}\right)$ formation in RAW 264.7 macrophage-like cells with 25,50 , or $100 \mu \mathrm{M}$. Luteolin and chrysin suppressed $\mathrm{PGE}_{2}$ formation equally well although luteolin had stronger effects on COX-2 protein expression and on superoxide and hydroxyl radical scavenging. Different mechanisms may be involved in their anti-inflammatory activity. These results were confirmed later [28].

Psotová et al. [29] compared 5 flavones and flavonols in their capacity to protect isolated rat cardiomyocytes from doxorubicininduced oxidative stress. Extracellular lactate dehydrogenase and cellular ADP and ATP protection was concentration-dependent for baicalein ( = 5,6,7-trihydroxyflavone) $>$ luteolin = apigenin > quercetin > kaempferol; all tested flavonoids were significantly better than dexrazosan, an agent currently used for adjuvant therapy during anthracycline antibiotic therapy. The cardioprotective effect did not correlate with the capacity to inhibit lipid peroxidation in microsomes and mitochondria, where the flavonols were superior to the flavones, especially to apigenin.

Kanazawa et al. [30] incubated HepG2 hepatic cells with various flavonoids $(10 \mu \mathrm{M})$ to determine whether these substances can penetrate into the nuclei and protect DNA from oxidative damage. Most of the tested flavonoids were incorporated in the nuclei at $250-450 \mathrm{pMol} / 10$ (7) cells after $30 \mathrm{~min}$ incubation, $8 \%$ of the luteolin in form of the aglycone, a lower rate than for other flavonoids. When oxidative stress was induced, luteolin $(-15 \%)$ and quercetin $(-25 \%)$ significantly reduced DNA damage as measured by formation of 8-oxo-7,8-dihydrodeoxyguanosine (8-OHdG [30]).

\section{In vivo}

Shimoi et al. [15] investigated the anticlastogenic effect of 12 structurally different flavonoids in whole body gamma-ray irradiated ICR mice [single gastric intubation $(5 \mu \mathrm{M} / \mathrm{kg})$ ] $6 \mathrm{~h}$ before irradiation $(1.5 \mathrm{~Gy})$. Luteolin had the most marked effect on reducing the frequencies of micronucleated reticulocytes in peripheral blood and also on inhibiting lipid peroxidation. A good correlation was observed between the anticlastogenic activity and the anti-oxidant activity of the 12 flavonoids $(200 \mu \mathrm{M})$ determined by the thiobarbituric acid method with methyl lineolate and $\mathrm{Fe}^{2+} / \mathrm{H}_{2} \mathrm{O}_{2}$.

Heroin, morphine and opiates are able to induce ROS formation in several cell types; they decrease the anti-oxidant defense system including enzymes: superoxide dismutase, catalase, and glutathione peroxidase; and anti-oxidants: glutathione (GSH), Se, and vitamins. Treatment of heroin-dependent mice with verbascoside or luteolin limited oxidative stress status and damage to DNA, proteins, and lipids in brain [31].

\section{Anti-Inflammatory and Anti-Allergic Effects of Luteolin \\ $\nabla$}

In vitro

Flavonoids have multiple and specific effects on inflammatory processes. An example of synergistic actions by luteolin and oth- 
er flavonoids was demonstrated by Ruiz et al. [32], who characterized the molecular mechanisms of flavonoids in inhibiting tumor necrosis factor- $\alpha$ (TNF- $\alpha$ ) induced interferon-inducible protein (IP-10) gene expression in the murine non-carcinoma intestinal epithelial cell line Mode-K. They tested various flavonoids at a concentration of $100 \mu \mathrm{M}$ and demonstrated that 3'-hydroxyflavone blocked TNF- $\alpha$ induced nuclear-factor kappa B (NF $\kappa$ B) transcriptional activity and IP-10 expression at the level of $\mathrm{NF} \kappa \mathrm{B} / \mathrm{I} \kappa \mathrm{B} \alpha$ phosphorylation/degradation by inhibiting the inhibitor of kappa B ( $\mathrm{I} \kappa \mathrm{B})$ kinase activity. Luteolin, apigenin, 3'-hydroxyflavone and genistein also displayed inhibitory effects on the TNF-induced NFKB signaling pathway, but with individual patterns on different steps of the signaling chain. Luteolin partially inhibited TNF-induced NF $\kappa B$ DNA binding activity followed by the complete blockade of NF $\kappa B$ transcriptional activity; $\mathrm{EC}_{50}$ were 20 to $27 \mu \mathrm{M}$.

In addition, apigenin and luteolin blocked protein kinase B (Akt) phosphorylation/activity; only luteolin caused long-lasting inhibition over $24 \mathrm{~h}$, too. Luteolin and 3'-hydroxyflavone induced interferon regulatory factor (IRF)-1 degradation. Genistein blocked IP-10 but not IL-6 expression through NFKB, IRF, and Akt independent mechanisms, demonstrating the functional diversity of flavonoids in inhibiting pro-inflammatory processes [32].

Essential mechanisms of luteolin's anti-inflammatory action are inhibition of inducible nitric oxygen synthase (iNOS) expression and NO production, scavenging of ROS, inhibition of ROS production and activation of anti-oxidant enzymes, inhibition of leukotriene production and release, suppression of pro-inflammatory cytokine expression, inhibition of the NFKB pathway, Akt and the mitogen-activated protein kinase (MAPK) pathway, inhibition of adhesion molecule membrane binding, inhibition of hyaluronidase and elastase activity, stabilization of mast cells, reduction of vascular permeability and modulation of cell membrane fluidity (see Table 1). Differences in efficiency or in thresholds reported by different authors may be due to the models analyzed or methodology. There is no space for a complete account of these parameters in individual studies. The following overview gives some additional information on selected effects in vitro and comparisons of luteolin with other flavonoids.

Luteolin as the active component isolated from Perilla frutescens inhibited NO production with an $\mathrm{IC}_{50}$ value of $6.9 \mu \mathrm{M}$ in LPSstimulated BV-2 microglial cells [33]. Incubation correlated well with reduced levels of iNOS mRNA and protein in another cell line. The molecular mechanism appeared to involve inhibition of NF $\kappa B$ activation which is not stimulus or cell specific as several flavonoids reduced macrophage colony-stimulating factor (MCSF)-induced proliferation without affecting cellular viability, and some also inhibited TNF- $\alpha$ production as well as iNOS expression and NO production in lipopolysaccharide (LPS)-activated bone marrow-derived macrophages, an effect that has been associated with the inhibition of the NF $\kappa$ B pathway [34]. Luteolin and quercetin were able to stimulate IL-10 expression at low concentrations ( $<50 \mu \mathrm{M})$. Analysis of the structure-activity relationship showed that four hydroxylations at positions $5,7,3^{\prime}$ and $4{ }^{\prime}$, together with the double bond at $\mathrm{C} 2-\mathrm{C} 3$ and the position of the $\mathrm{B}$ ring at 2 , seem to be necessary for the highest anti-inflammatory effect. This is exactly the structure of luteolin.

Luteolin, quercetin, and apigenin completely protected RINm5F (RIN) rat insulinoma cells against interleukin-1 $\beta$ (IL-1 $\beta$ )- and interferon- $\gamma($ IFN- $\gamma)$-mediated cytotoxicity [35].
In LPS-stimulated murine macrophages RAW 264.7 luteolin inhibited TNF- $\alpha$ and IL-6 release, tyrosine phosphorylation, NF $\kappa B$ mediated gene expression, and Akt phosphorylation. Luteolin was more effective than luteolin 7-glucoside, quercetin, genistein, hesperitin and eriodictyol, with an $\mathrm{IC}_{50}$ value of less than $1 \mu \mathrm{M}$ for TNF- $\alpha$ release [36].

In two examinations of 37 and 45 flavonoids and related compounds for inhibition of IL-4 and IL-13 production in basophils stimulated with anti-IgE antibody plus IL-3, ayanin (quercetin $3,4^{\prime}, 7$-trimethyl ether), luteolin and apigenin were the strongest inhibitors, with $\mathrm{IC}_{50}$ values of $2-5 \mu \mathrm{g} / \mathrm{mL}(1-2 \mu \mathrm{M})$ [37], [38].

Flavonoids are the active principles for inhibition of IL-5 bioactivity in the Japanese plant Kummerowia striata Thunb. IL-5 is a chemotactic factor of eosinophils, and promotes the growth and survival of eosinophils, which play an important role in eosinophilia-associated allergic inflammation. Luteolin inhibited IL-5 bioactivity with an $\mathrm{IC}_{50}$ value of $18.7 \mu \mathrm{M}$, approximately equal to that of apigenin and stronger than that of kaempferol. The most effective compound, however, was luteolin 4'-O-glucopyranoside with $\mathrm{IC}_{50}=3.7 \mu \mathrm{M}$, and $95 \%$ inhibition at $30 \mu \mathrm{M}$ [39].

Enhanced CD40 ligand expression in the human basophilic cell line KU812 in response to $12 \mathrm{~h}$ incubation with A23187 plus PMA was significantly suppressed by 10 or $30 \mu \mathrm{M}$ of luteolin, and less effectively by apigenin, fisetin and quercetin at $30 \mu \mathrm{M}$, whereas myricetin failed to inhibit [40].

Hexosaminidase release from RBL-2H3 cells (degranulation marker) was employed as an estimate for anti-allergic actions. Among 22 flavonoid compounds tested, luteolin, apigenin, diosmetin, fisetin, and quercetin were found to be most active with $\mathrm{IC}_{50}$ values below $10 \mu \mathrm{M}$ [41].

Apigenin, chrysin and luteolin dose-dependently inhibited both pro-inflammatory cytokine (TNF- $\alpha$, IL- $1 \beta$ and IL-6) production and metabolic activity of LPS-stimulated peripheral blood mononuclear cells (PBMC). Monocytes were specifically eliminated in PBMC at low concentrations $(\approx 8 \mu \mathrm{M})$, with apigenin appearing as the most potent, while quercetin and naringenin had virtually no effects [42].

A selection of 26 naturally occurring flavonoids was investigated for inhibition of NO production in LPS-activated RAW 264.7 cells. The most active were apigenin, wogonin, and luteolin, having $\mathrm{IC}_{50}$ values of 23,17 , and $27 \mu \mathrm{M}$, respectively, while AMT, a synthetic selective iNOS inhibitor, had an $\mathrm{IC}_{50}$ value of $0.09 \mu \mathrm{M}$ [43]. Verbeek et al. [44] evaluated the inhibiting effects of various flavonoids on antigen-specific proliferation and IFN- $\gamma$ production by human (multiple sclerosis) and murine experimental autoimmune encephalomyelitis (EAE) autoreactive T cells in vitro. Apigenin and luteolin were strong inhibitors of both murine and human T-cell responses while fisetin, quercetin, morin and hesperitin were ineffective. These promising in vitro results, however, were not confirmed by an in vivo investigation [45]. Luteolin was less effective than apigenin as a competitive inhibitor of hyaluronidase [46]. However, the relative potency depends not only on the structure of the flavonoid, but also varies for different kinds of hyaluronidases [47].

Luteolin $(1 \mu \mathrm{M})$ caused a significant elevation of the collagen content, alkaline phosphatase activity, and osteocalcin secretion in osteoblasts [48]. Yanoshita et al. [49] examined several flavonoids for inhibitory effects on the 2-lysophospholipid (lyso-PAF) acetyltransferase using homogenates of a rat mucosal-type mastocytoma cell line, RBL-2H3 as an enzyme source. Of the flavonoids tested, luteolin and quercetin exhibited significant inhibi- 
Table 1 Anti-inflammatory mechanisms investigated with luteolin.

\begin{tabular}{|c|c|c|}
\hline Target & Effect of luteolin & Publication source(s) \\
\hline iNOS & Suppresses iNOS expression & [33], [35], [34], [43], [81], [82], [84] \\
\hline NO & Supresses NO production & [33], [35], [48], [34], [43], [56], [81], [82] \\
\hline $\mathrm{H}_{2} \mathrm{O}_{2}$ & Supresses $\mathrm{H}_{2} \mathrm{O}_{2}$ production and scavenges $\mathrm{H}_{2} \mathrm{O}_{2}$ & [85] \\
\hline SOD-1 & Increases SOD- 1 expression & [91] \\
\hline PGE-2 & Suppresses PGE-2 production & [48], [81] \\
\hline PGD-2 & Inhibits PGD-2 release from human mast cells & [51], [52] \\
\hline Leukotrienes & Inhibits leukotriene release from human mast cells & [51], [52] \\
\hline Leukotriene B4 & inhibits LT B4 synthesis & [87] \\
\hline Leukotriene C4 & No effect & [37] \\
\hline Thromboxane B2 & Inhibits TX B2 synthesis & [87] \\
\hline Histamine & Inhibits histamine release from human mast cells & {$[51],[52]$} \\
\hline GM-CSF & Inhibits GM-CSF release from human mast cells & {$[51],[52]$} \\
\hline TNF- $\alpha$ & Suppresses TNF- $\alpha$ expression & {$[48],[34],[36],[42],[53],[55],[56],[81],[93]$} \\
\hline cox-2 & Suppresses COX-2 expression & {$[28],[57],[81],[84]$} \\
\hline mPGES-1 & Suppresses MPGES- 1 expression & [28] \\
\hline IL-1 $\beta$ & Suppresses IL-1ß expression & [42] \\
\hline IL-4 & Suppresses IL-4 expression & {$[37],[38]$} \\
\hline IL-5 & Inhibits bioactivity of IL-5 & [39] \\
\hline IL-6 & Suppresses IL-6 expression & [48], [36], [42], [81], [91] \\
\hline IL-8 & Suppresses IL-8 expression & [91] \\
\hline IL-10 & Stimulates IL-10 expression & [34] \\
\hline IL-13 & Suppresses IL-13 expression & [37], [38] \\
\hline MCP-1 & Reduces elevated MCP-1 levels & [91] \\
\hline CCL5 (RANTES) & Reduces elevated CCL5 levels & [91] \\
\hline IFN- $\gamma$ & Reduces IFN- $\gamma$ production in vitro, not in vivo & {$[42],[45]$} \\
\hline Complement & Inhibits classical pathway (esp. glycosides) & [89], [90] \\
\hline Complement & No effect on classical pathway & [88] \\
\hline MAPK & Reduces MAPK phosphorylation & [56], [82] \\
\hline ERK & Suppresses IgE-stimulated activation of ERK & [51], [52] \\
\hline JNK & Suppresses IgE-stimulated activation of JNK & [51], [52] \\
\hline IKK & Inhibits IKK phosphorylation & {$[81]$} \\
\hline $\mid \kappa \mathrm{B} \alpha$ & Blocks I $\kappa$ B $\alpha$ degradation & {$[33],[36],[81]$} \\
\hline $\mid \kappa \mathrm{B} \alpha$ & Does not inhibit $/ \kappa B \alpha$ degradation & {$[85]$} \\
\hline$N F \kappa B$ & Inhibits DNA binding and transcription & [32], [35], [36], [81], [82] \\
\hline $\mathrm{NF} \kappa \mathrm{B}$ & $\begin{array}{l}\text { Does not inhibit NFKB nuclear translocation, DNA binding or } \\
\text { phosphorylation but inhibits transcription }\end{array}$ & {$[85]$} \\
\hline AP-1 & Induces AP-1 DNA binding & {$[81],[83]$} \\
\hline Akt & Inhibits phosphorylation and activity & {$[32],[36],[81],[82]$} \\
\hline IRF & Induces IRF- 1 transcription factor degradation & {$[32]$} \\
\hline IP-10 & Suppresses IP-10 expression & [32], [91] \\
\hline CD40 ligand & Suppresses CD40 ligand expression & {$[38],[40]$} \\
\hline ICAM-1 & Inhibits LPS-stimulated ICAM-1 expression in vivo (mouse) & [55] \\
\hline Rho GTPase & $\begin{array}{l}\text { Reduces Rho GTPase activity and monocyte transepithelial } \\
\text { migration }\end{array}$ & [54] \\
\hline Tyrosine kinase & Suppresses tyrosyl phosphorylation & [36], [86] \\
\hline Hyaluronidase & Inhibits native hyaluronidase more than recombinant & [46], [47] \\
\hline Lyso-PAF-AcTF & Inhibits Lyso-PAF-AcTF specifically & {$[49]$} \\
\hline PAF & Inhibits PAF production & {$[49]$} \\
\hline Vascul. Permeabil. & Reduces increased vascular permeability & {$[50]$} \\
\hline Lipid rafts & Blocks lipid raft accumulation & [56] \\
\hline Mast cells & blocks mast cell activity and T-cell activation & [51], [52], [92] \\
\hline
\end{tabular}

tory effects ( $\mathrm{IC}_{50}, 45 \mu \mathrm{M}$ and $80 \mu \mathrm{M}$, respectively), whereas other structurally-related flavonoids were ineffective.

In vivo

Topical application of luteolin at concentrations of 20 and $100 \mu \mathrm{g} /$ site significantly reduced the number of scratching incidents associated with dinitrochlorobenzene-induced passive cutaneous anaphylaxis in mice, and a similar tendency was also observed in histamine-, serotonin- and compound 48/80-evoked cutaneous reactions. Vascular permeability and ear thickness increase were also significantly reduced, attributed to inhibition of mediators and mediator release [50].

A preventive and ameliorating effect of luteolin on clinical symptoms in atopic dermatitis-prone mice was found after internal application [38]. Intraperitoneal injection of luteolin or baicalein doses of $0.1 \mathrm{mg} / \mathrm{kg}$ reduced antibody plus dinitrofluorobenzene-induced mouse ear edemas to $30 \%$ and $50 \%$, respectively. Quercetin had only a small influence [51], [52]. 
Various flavonoids inhibited LPS-induced TNF- $\alpha$ production from macrophages in vitro, but only luteolin showed in vivo activity when administered orally. Serum TNF- $\alpha$ production was inhibited to about $20-25 \%$ in a highly significant manner by 0.1 and $1 \mathrm{mg} /$ mouse luteolin (p.o.). Only luteolin or quercetin inhibited TPA-induced ear edema. The authors suggest that the structure of luteolin as 3',4',5,7-tetrahydroxyflavone is most suitable for oral anti-inflammatory activity [53].

Rats sensitized for acute and chronic EAE, an experimental model of multiple sclerosis, were treated with oral doses of luteolin and quercetin [54]. Luteolin substantially suppressed clinical symptoms and prevented relapse much stronger than quercetin when administered either before or after disease onset. Luteolin treatment reduced inflammation and axonal damage in the central nervous system (CNS) by preventing monocyte migration across the brain endothelium; this was due to modulation of the activity of Rho GTPases, signal transducers involved in transendothelial migration. Mice receiving LPS (Salmonella enteriditis LPS $32 \mathrm{mg} / \mathrm{kg}$, i.p.) exhibited high mortality, with only $4.1 \%$ of the animals surviving seven days after LPS challenge. Mice that had received luteolin $(0.2 \mathrm{mg} / \mathrm{kg}$, i.p. $)$ before LPS had an increased survival rate of $48 \%$. Luteolin decreased LPS-induced tumor TNF- $\alpha$ production and ICAM-1 expression in the liver and abolished leukocyte infiltration in liver and lung [55]. These results were confirmed for oral application of luteolin and other flavonoids in the TNF- $\alpha$ triggered collagen-induced arthritis (CIA) mouse model of rheumatoid arthritis. Inhibitory effects were due to regulation of signaling pathways (NF $\kappa$ B, MAPK, and FcRI expression). Accumulation of lipid rafts, which is the critical step for signaling, was blocked [56]. Oral administration of luteolin (10 and $50 \mathrm{mg} / \mathrm{kg}$ ) to mice efficiently suppressed carrageenan-induced paw edema. Results derived from whole blood assay for COX and from the RT-PCR assay indicate that luteolin may be a potent selective inhibitor of COX-2 mRNA expression [57].

\section{Bioavailability and Toxicological Aspects \\ $\nabla$}

\section{Systemic bioavailabilty}

The physiological role of an anti-oxidant is modulated in a complex way, depending on factors like resorption, its bioavailability at a specific site in the organism, partition coefficient between aqueous and lipophilic phases, its ability to chelate with metal ions, or its distribution between, and binding to certain cell compartments.

Zhou et al. [58] found that luteolin is passively resorbed in the jejunum and duodenum of the rat, and less in the colon and ileum. Application of identical amounts $(14.3 \mathrm{mg} / \mathrm{kg}$ ) of pure luteolin and in the matrix of a peanut hull extract revealed that absorption of the latter was higher $\left(C_{\text {max }}: 8.34 \mathrm{vs} .1 .97 \mu \mathrm{g} / \mathrm{mL}\right.$ or 29.2 vs. $6.9 \mu \mathrm{M})$.

Flavonoid glycosides are cleaved to their aglycones in the intestinal mucosa, and the aglycones are glucuronated by UDP-glucuronosyl transferases before release into blood serum [2]. Wittemer et al. [59] investigated pharmacokinetics of aqueous artichoke extracts containing $14.4 \mathrm{mg}$ and $35.2 \mathrm{mg}$ luteolin 7-O-glucoside in humans. Neither luteolin nor its glycosides were found in urine or plasma, but only their phase II conjugates. Maximal plasma levels of about $0.2 \mu \mathrm{M}$ were reached after $30-40 \mathrm{~min}$. The time-concentration profile was biphasic with a fast distribution and a slow elimination phase. Terminal elimination half- time was $2.5 \mathrm{~h}$, and $2 \%$ of the applied dose were eliminated renally as luteolin conjugates.

Plasma concentrations observed in these experiments may suffice under certain conditions to display measurable anti-oxidant activity; luteolin inhibited $\mathrm{Cu}^{2+}$-induced oxidation of LDL-cholesterol in concentrations from $28 \mathrm{ng} / \mathrm{mL}(0.1 \mu \mathrm{M})$ upward [60]. Anti-oxidant properties are to a large extent attributable to hydroxylation in positions $3^{\prime}$ and $4^{\prime}$; it is there, where flavonoids are preferentially glucuronidized during resorption in the gut [61]. This might reduce the flavonoids' anti-oxidant potential. However, several human tissues, e.g., neutrophil granulocytes and CaCo-2 cells, are able to cleave luteolin glucuronides, and increase their activity when stimulated by pro-inflammatory substances [62]. Thus, these glucuronides may function as a depot and the full anti-oxidant capacity of luteolin may be re-established right at the site of inflammation.

\section{Topical bioavailability}

In vivo skin penetration studies of the flavones apigenin, luteolin, and apigenin $7-O$ - $\beta$-glucoside were carried out with nine healthy, female volunteers. During 7 hours the decline of flavonoid concentration in a saturated aqueous alcoholic solution filled in glass application chambers was repeatedly measured by spectrophotometry at fixed time periods. The maximal fluxes were calculated. From the observed time course it was concluded that apigenin and luteolin were not only adsorbed at skin surface but penetrated into deeper skin layers [63]. This indirect evidence of penetration should be confirmed by standard penetration studies such as the tape-stripping method. Skin penetration of luteolin and its glycosides is a prerequisite for their topical use as antiphlogistic agents in dermatology.

\section{Toxicological aspects}

$\mathrm{LD}_{50}$ values of $>180 \mathrm{mg} / \mathrm{kg}$ i.p. were determined in mice [64], and $411 \mathrm{mg} / \mathrm{kg}$ in rats [65]. Oral $\mathrm{LD}_{50}$ in mice was reported as $>2500 \mathrm{mg} / \mathrm{kg}$ [65]. Luteolin was protective on H4IIE cells in concentrations up to $50 \mu \mathrm{M}$, but displayed cytotoxic effects in the NRU test with an $\mathrm{IC}_{50}$ of $100 \mu \mathrm{M}$ [22].

Both luteolin $\left(\mathrm{IC}_{50}=12.5 \mu \mathrm{M}\right)$ and quercetin $\left(\mathrm{IC}_{50}=45.5 \mu \mathrm{M}\right)$ displayed anti-leishmanial activity in vitro. Whereas quercetin displays non-specific toxic effects on normal human PBMC, luteolin was non-toxic. Further studies have to prove whether luteolin may serve as a lead for anti-leishmanial therapy [66].

Luteolin, in contrast to quercetin and rhamnetin, had no mutagenic effects in the Ames mutagenicity test [67], but luteolin (and 25 other flavonoids) inhibited mutagenicity induced by aflatoxin B in Salmonella typhimurium TA 100 by 70\% [68], and in the comet assay [20]. Kawanishi et al. [69] investigated the capacity of phytal anti-oxidants to play a paradoxical role as prooxidant, and thus damage instead of protect DNA structure under certain experimental conditions. Some flavonoids like quercetin, genistein and catechins were indeed harmful in $\mathrm{H}_{2} \mathrm{O}_{2}$-generating systems or after metabolic activation, but luteolin was safe. For more information on earlier work on flavonoid safety and pharmacology the reader is referred to the extensive review by Middleton et al. [70].

\section{Conclusions}

\section{$\nabla$}

Luteolin is a moderately effective anti-oxidant in simple standard in vitro tests, but may exert surprisingly high efficacy down 
to the nanomolar range in more complex assays, cellular or in vivo settings. It is not always clear whether conditions modify the anti-oxidant capacity of the substance, or whether additional pharmacological activity is involved. The 0 -di-OH catechol group of the $\mathrm{B}$ ring is able to chelate metal ions and contributes strongly to the anti-oxidant capacities. Luteolin has only weak pro-oxidative capacities and will not undergo redox cycling, making it a safer anti-oxidant than quercetin.

The daily dietary intake of luteolin is very low in comparison to total flavonoid uptake (approx. $1 \%$ ), so that the contribution to total anti-oxidant capacity in our nutrition may not be such a relevant factor. Epidemiological data nevertheless indicate a physiological role of flavones and especially of luteolin. This may be due to more specific mechanisms than just radical scavenging.

Luteolin exerts numerous effects in vivo and in vitro, which can reduce inflammatory processes in cells stimulated by pro-inflammatory factors. This includes inhibition of cytokine production, inhibition of enzymes and enzyme expression, suppression of regulatory proteins (especially of the $\mathrm{NF} \kappa \mathrm{B}$ pathway), and radical scavenging. These effects may be related more or less to its anti-oxidant capacity, but some are very specific and distinct from effects of other flavonoids which have similar anti-oxidant properties.

When compared to other flavonoids, luteolin was usually among the most effective ones, or the most effective. For certain pharmacological effects its structure was even regarded as optimal. Some processes like TNF- $\alpha$ release from murine macrophages had $\mathrm{IC}_{50}$ values as low as $1 \mu \mathrm{M}$. This is higher than serum levels expected from everyday nutritional intake, but may be reached by supplementation. More quantitative investigations on luteolin pharmacokinetics, possible storage effects when bound to plasma or when biotransformed to glucuronides and bioavailability at specific action sites are needed to realistically estimate the pharmacological potential of luteolin. Results obtained with luteolin (or other flavonoid) glycosides in vitro have to be regarded sceptically, since these molecules are cleaved during uptake and will not be found in plasma, The aglycone, however, may be set free from its conjugates in specific tissues and exert those effects found experimentally in vitro. Some in vivo studies have already demonstrated that strong effects were observed after intraperitoneal or after oral administration of non-toxic doses of luteolin.

New instruments were developed during the last decades which now allow to estimate dietary contents of total flavonoids and their most important subclasses: the USDA database lists flavones, flavonols, flavanones, flavan-3-ols, anthocyanidins, as well as isoflavones and proanthocyanidins, and a number of important single components. Investigations in different populations have revealed, that mean total flavonoid intake is usually in the order of $100-200 \mathrm{mg} / \mathrm{d}$. Flavonols (with quercetin and kaempferol as main components) contribute 5-20 mg/d, flavones only about $1 \mathrm{mg}$, often less. Up to $90 \%$ of the flavone fraction may be apigenin, leaving about $0.1 \mathrm{mg} / \mathrm{d}$ for luteolin. Expectations to find health effects of flavone (or even luteolin) intake by epidemiological correlations should be moderate. It is surprising, after all, that there are indeed some promising new data for these substances. This concerns some species of cancer (by mechanisms which are not subject of this article), but also cardiovascular disease (CVD), which is nowadays regarded as the result of long-lasting inflammatory processes in combination with other factors like high levels of (oxidized) blood lipids.
Risk reduction for CVD by flavonoid intake has been suggested in a number of studies, e.g., by Knekt et al. [71] with 20 years follow-up of more than 5000 Finnish men and women. In a 28 years follow-up cohort study with 9000 Finnish people, a correlation of CVD risk with apple intake was reported, but not with the main flavonol component quercetin [72].

Marniemi et al. [73] assessed dietary and serum vitamins and minerals for prediction of acute myocardial infarction (AMI) and stroke in elderly subjects in Finland. In a population-based health survey with special emphasis on the diet, 361 men and 394 women aged between 65-99 years were followed up for up to 10 years. Low intakes of vitamin D emerged as the sole predictor for stroke, while high dietary intakes of luteolin and kaempferol were associated with lowered risk of AMI in a statistically significant way $(\mathrm{p}<0.01)$.

Mink et al. [74] investigated dietary intake of total flavonoids and 7 subclasses to evaluate the association between flavonoid intake and CVD mortality in 34,489 postmenopausal women in the Iowa Women's Health Study. Mean total flavonoid intake was $13.9 \mathrm{mg} / \mathrm{d}$, quercetin $9.7 \mathrm{mg} / \mathrm{d}$, kaempferol $3.4 \mathrm{mg} / \mathrm{d}$, myricetin $0.74 \mathrm{mg} / \mathrm{d}$, luteolin $0.05 \mathrm{mg} / \mathrm{d}$, and apigenin $0.01 \mathrm{mg} / \mathrm{d}$. After 16 years of follow-up no significant inverse associations were observed for total flavonoid intake, but between anthocyanidins and CHD, CVD, and total mortality; between flavanones and CHD; and between flavones and total mortality (OR: 0.88 $(0.82-0.96))$. No association was found between flavonoid intake and stroke mortality. In an earlier evaluation of the same study population after 10 years follow-up, Yochum et al. [75] had analyzed single flavonols and flavones. Quercetin and kaempferol significantly reduced CHD death, while luteolin was at the border of significance [OR: $0.8(0.63-1.02)]$.

It appears that nutritional uptake of luteolin or its glycosides in very low amounts contributes to protection from cardiovascular disease (but not from stroke); there are, however, also some studies which could not find such a correlation [76], [77].

Besides inflammatory and allergic reactions, cardiovascular disease and cancer, various indications like diabetes mellitus, multiple sclerosis, or leishmaniasis have been discussed as possible therapeutic fields for luteolin. Luteolin is already marketed as a nutrition supplement providing 100 times higher dosage than normal diet, with reference to anti-ageing and specific therapeutic activities. This is questionable in view of the scarce clinical and safety data for such high amounts. Recent publications indicate possible interactions of luteolin with the cytochrome P450 system and other detoxification systems [78], [79], so that highdose oral uptake needs further scientific backing. As far as epidemiological studies on nutritional effects are concerned, the question of luteolin uptake in form of its glycosides or the aglycone needs also further elucidation before consequences for supplementation can be drawn. An interesting application of luteolin was presented by Ahlenstiel et al. [80] for the preservation of renal transplantation tissue.

Considering the biotransformation in which flavonoids and also luteolin are involved after oral uptake the topical application of luteolin for inflammatory skin diseases may be very interesting. Preliminary pharmacokinetic data suggest that luteolin is able to penetrate into deeper skin layers [63] and might be used for the treatment of inflammatory and allergic skin diseases as well as for skin protection from solar radiation. Skin damage from solar radiation is mediated via generation of reactive oxygen species and radicals, which induce inflammatory processes. Luteolin may counteract this process by its anti-oxidant as well as anti- 
inflammatory mechanisms. Protection from solar induced erythema by topical application of luteolin and long-term anti-ageing effects on dermal structure should be an interesting field for further investigations.

\section{Acknowledgements}

The competence Center Skintegral ${ }^{\circledR}$ is supported by Software AG-Stiftung, Zukunftsstiftung Gesundheit, Dr. Hauschka-Stiftung and WALA Heilmittel GmbH.

\section{References}

1 USDA databank for the flavonoid content of selected foods, 2nd release 2007. Available at http://www.ars.usda.gov/nutrientdata; Accessed June 13, 2008

2 Schempp CM, Wähling A, Lange E. Method for the production of flavonoid-containing compositions and use thereof. European patent EP 1 648566 B1; 2008

3 Heilmann J, Merfort I. Aktueller Kenntnisstand zum Metabolismus von Flavonoiden. II. Resorption und Metabolismus von Flavonen, Flavanonen, Flavanen, Procyanidinen und Isoflavonoiden. Pharm Unserer Zeit 1998; 27: $173-83$

4 Huang $D, O u$, Prior RL. The chemistry behind antioxidant capacity assays. J Agric Food Chem 2005; 53: 1841 - 56

5 Apak R, Güçlü K, Demirata B, Ozyürek M, Celik SE, Bektaşoglu B et al. Comparative evaluation of various total antioxidant capacity assays applied to phenolic compounds with the CUPRAC assay. Molecules 2007; $12: 1496-547$

6 Havsteen $B H$. The biochemistry and medical significance of the flavonoids. Pharmacol Ther 2002; 96: 67-202

7 Heim KE, Tagliaferro AR, Bobilya DJ. Flavonoid antioxidants: chemistry, metabolism and structure-activity relationships. J Nutr Biochem 2002; 13: $572-84$

8 Belyakov VA, Roginsky VA, Bors W. Rate constant for the reaction of peroxyl free radical with flavonoids and related compounds as determined by the kinetic chemoluminescence method. J Chem Soc [Perkin 2]; 1995: 2319-36

9 Jovanovic SV, Steenken S, Hara Y, Simic MG. Reduction potential of flavonoid and model phenoxyl radicals. Which ring in flavonoids is responsible for antioxidant activity? J Chem Soc [Perkin 2]; 1996: 2497-504

10 Rice-Evans CA, Miller NJ, Paganga G. Structure-antioxidant activity relationships of flavonoids and phenolic acids. Free Radic Biol Med 1996; 20: $933-1056$

11 Brown JE, Khodr H, Hider RC, Rice-Evans CA. Structural dependence of flavonoid interactions with $\mathrm{Cu}^{2+}$ ions: implications for their antioxidant properties. Biochem J 1998; 330: 1173-8

12 Pietta PG. Flavonoids as antioxidants. J Nat Prod 2000; 63: 1035-42

13 Romanová D, Vachálková A, Cipák L, Ovesná Z, Rauko P. Study of antioxidant effect of apigenin, luteolin and quercetin by DNA protective method. Neoplasma 2001; 48: $104-7$

14 Galvez J, de la Cruz JP, Zarzuelo A, Sanchez de la Cuesta F. Flavonoid inhibition of enzymic and nonenzymic lipid peroxidation in rat liver differs from its influence on the glutathione-related enzymes. Pharmacology 1995; 51: $27-33$

15 Shimoi K, Masuda S, Shen B, Furugori M, Kinae N. Radioprotective effect of antioxidative flavonoids in gamma-ray irradiated mice. Carcinogenesis 1994; 15: 2669-72

16 Gal S, Lichtenberg D, Bor A, Pinchuk I. Copper-induced peroxidation of phosphatidylserine-containing liposomes is inhibited by nanomolar concentrations of specific antioxidants. Chem Phys Lipids 2007; 150: $86-203$

17 Hirano R, Sasamoto W, Matsumoto A, Itakura H, Igarashi O, Kondo K. Antioxidant ability of various flavonoids against DPPH radicals and LDL oxidation. J Nutr Sci Vitaminol (Tokyo) 2001; 47: 357-62

18 Horváthová K, Novotńy L, Vachálková A. The free radical scavenging activity of four flavonoids determined by the comet assay. Neoplasma 2003; $50: 291-5$

19 Horváthová K, Novotny L, Tóthová D, Vachálková A. Determination of free radical scavenging activity of quercetin, rutin, luteolin and apigenin in $\mathrm{H}_{2} \mathrm{O}_{2}$-treated human ML cells K562. Neoplasma 2004; 51: 395 -9
20 Horváthová K, Chalupa L, Sebova D, Tóthová D, Vachálková A. Protective effect of quercetin and luteolin in human melanoma HMB-2 cells. Mutat Res 2005; 565: 105-12

21 Noroozi M, Angerson WJ, Lean ME. Effects of flavonoids and vitamin C on oxidative DNA damage to human lymphocytes. Am J Clin Nutr 1998; $67: 1210-8$

22 Steffan B. Inhaltsstoffe aus Pflanzen der indonesischen Volksmedizin (Jamu): Isolierung, Identifizierung, und Charakterisierung der antioxidativen Eigenschaften [dissertation]. Düsseldorf: Heinrich Heine Universität; 2005

23 Pérez-García F, Adzet T, Canigueral S. Activity of artichoke leaf extract on reactive oxygen species in human leukocytes. Free Radic Res 2000; 33: $661-5$

24 Kohen R, Nyska A. Oxidation of biological systems: oxidative stress phenomena, antioxidants, redox reactions, and methods for their quantification. Toxicol Pathol 2002; 30: 620-50

25 Gebhardt R, Rexhepaj R, Fausel M. Vergleich der antioxidativen und hepatoprotektiven Wirkung von Flavonoiden aus Blattextrakten der Artischocke (Cynara scolymus) an Hepatocytenkulturen unter Einwirkung toxischer Hydroperoxide. Phytopharmakaforschung 2000, Tagung der Ges Phytotherapie und Ges Arzneipflanzenforschung; Bonn: 1998

26 Wolfe KL, Liu RH. Cellular antioxidant activity (CAA) assay for assessing antioxidants, foods, and dietary supplements. J Agric Food Chem 2007; 55: $8896-907$

27 Harris GK, Qian Y, Leonard SS, Sbarra DC, Shi X. Luteolin and chrysin differentially inhibit cyclooxygenase-2 expression and scavenge reactive oxygen species but similarly inhibit prostaglandin-E2 formation in RAW 264.7 cells. J Nutr 2006; 136: 1517-21

28 Wang XG, Chen GY, Chen MP. Effect of luteolin on COX-2 and mPGES-1 expression in LPS-induced RAW264.7 cells. Zhong yao cai - J Chin Med Mater 2008; 30: $1263-6$

29 Psotová J, Chlopcíková S, Miketová P, Hrbác J, Simánek V. Chemoprotective effect of plant phenolics against anthracycline-induced toxicity on rat cardiomyocytes. Part III. Apigenin, baicalelin, kaempferol, luteolin and quercetin. Phytother Res 2004; 18: 516- 21

30 Kanazawa K, Uehara M, Yanagitani H, Hashimoto T. Bioavailable flavonoids to suppress the formation of 8-OHdG in HepG2 cells. Arch Biochem Biophys 2006; 455: $197-203$

31 Qiusheng Z, Yuntao Z, Rongliang Z, Dean G, Changling L. Effects of verbascoside and luteolin on oxidative damage in brain of heroin treated mice. Pharmazie 2005; 60: 539-43

32 Ruiz PA, Haller D. Functional diversity of flavonoids in the inhibition of the proinflammatory NF-kappaB, IRF, and Akt signaling pathways in murine intestinal epithelial cells. J Nutr 2006; 136: 664 - 71

$33 \mathrm{Kim}$ JS, Lee HJ, Lee MH, Kim J, Jin C, Ryu JH. Luteolin inhibits LPS-stimulated inducible nitric oxide synthase expression in BV-2 microglial cells. Planta Med 2006; 72: 65-8

34 Comalada M, Ballester I, Bailón E, Sierra S, Xaus J, Gálvez J et al. Inhibition of pro-inflammatory markers in primary bone marrow-derived mouse macrophages by naturally occurring flavonoids: analysis of the structure-activity relationship. Biochem Pharmacol 2006; 72: 010-21

35 Kim EK, Kwon KB, Song MY, Han MJ, Lee JH, Lee YR. Flavonoids protect against cytokine-induced pancreatic beta-cell damage through suppression of nuclear factor kappaB activation. Pancreas 2007; 35: 1 -9

36 Xagorari A, Papapetropoulos A, Mauromatis A, Economou M, Fotsis T, Roussos C. Luteolin inhibits an endotoxin-stimulated phosphorylation cascade and proinflammatory cytokine production in macrophages. J Pharmacol Exp Ther 2001; 296: 181 - 7

37 Hirano T, Higa S, Arimitsu J, Naka T, Shima Y, Ohshima S et al. Flavonoids such as luteolin, fisetin and apigenin are inhibitors of interleukin- 4 and interleukin-13 production by activated human basophils. Arch Allergy Immunol 2004; 134: 135-40

38 Kawai M, Hirano T, Higa S, Arimitsu J, Maruta M, Kuwahara Y et al. Flavonoids and related compounds as anti-allergic substances. Allergol Int 2007; 56: $113-23$

39 Park KY, Lee SH, Min BK, Lee KS, Choi JS, Chung SR et al. Inhibitory effect of luteolin 4'-O-glucoside from Kummerowia striata and other flavonoids on interleukin-5 bioactivity. Planta Med 1999; 65: 457-9

40 Hirano T, Arimitsu J, Higa S, Naka T, Ogata A, Shima Y et al. Luteolin, a flavonoid, inhibits CD40 ligand expression by activated human basophils. Int Arch Allergy Immunol 2006; 140: 150-6

41 Cheong H, Ryu SY, Oak MH, Cheon SH, Yoo GS, Kim KM. Studies of structure activity relationship of flavonoids for the anti-allergic actions. Arch Pharm Res 1998; 21: 78 - 80 
42 Hougee S, Sanders A, Faber J, Graus YM, van den Berg WB, Garssen Jet al. Decreased pro-inflammatory cytokine production by LPS-stimulated PBMC upon in vitro incubation with the flavonoids apigenin, luteolin or chrysin, due to selective elimination of monocytes/macrophages. Biochem Pharmacol 2005; 69: 241 -8

$43 \mathrm{Kim}$ HK, Cheon BS, Kim YH, Kim SY, Kim HP. Effects of naturally occurring flavonoids on nitric oxide production in the macrophage cell line RAW 264.7 and their structure-activity relationships. Biochem Pharmacol 1999; 58: 759-65

44 Verbeek R, Plomp AC, van Tol EA, van Noort JM. The flavones luteolin and apigenin inhibit in vitro antigen-specific proliferation and interferon-gamma production by murine and human autoimmune T cells. Biochem Pharmacol 2004; 68: 621 -9

45 Verbeek $R$, van Tol EA, van Noort JM. Oral flavonoids delay recovery from experimental autoimmune encephalomyelitis in SJL mice. Biochem Pharmacol 2005; 70: 220-8

46 Kuppusamy UR, Khoo HE, Das NP. Structure-activity studies of flavonoids as inhibitors of hyaluronidase. Biochem Pharmacol 1990; 40: $397-401$

47 Hertel W, Peschel G, Ozegowski JH, Müller PJ. Inhibitory effects of triterpenes and flavonoids on the enzymatic activity of hyaluronic acidsplitting enzymes. Arch Pharm (Weinheim) 2006; 339: 313-8

48 Choi EM. Modulatory effects of luteolin on osteoblastic function and inflammatory mediators in osteoblastic MC3T3-E1 cells. Cell Biol Int 2007; 31: 870-7

49 Yanoshita R, Chang HW, Son KH, Kudo I, Samejima Y. Inhibition of lysoPAF acetyltransferase activity by flavonoids. Inflamm Res 1996; 45: $546-9$

50 Baolin L, Weiwei $W$, Ning T. Topical application of luteolin inhibits scratching behavior associated with allergic cutaneous reaction in mice. Planta Med 2005; 71: 424-8

51 Kimata $M$, Inagaki $N$, Nagai $H$. Effects of luteolin and other flavonoids on IgE-mediated allergic reactions. Planta Med 2000; 66: 25 - 9

52 Kimata M, Shichijo M, Miura T, Serizawa I, Inagaki N, Nagai $\mathrm{H}$. Effects of luteolin, quercetin and baicalein on immunoglobulin E-mediated mediator release from human cultured mast cells. Clin Exp Allergy 2000; 30: $501-8$

53 Ueda H, Yamazaki C, Yamazaki M. Luteolin as an anti-inflammatory and anti-allergic constituent of Perilla frutescens. Biol Pharm Bull 2002; 25: $1197-202$

54 Hendriks JJ, Alblas J, van der Pol SM, van Tol EA, Dijkstra CD, de Vries HE. Flavonoids influence monocytic GTPase activity and are protective in experimental allergic encephalitis. J Exp Med 2004; 200: 1667-72

55 Kotanidou A, Xagorari A, Bagli E, Kitsanta P, Fotsis T, Papapetropoulos A et al. Luteolin reduces lipopolysaccharide-induced lethal toxicity and expression of proinflammatory molecules in mice. Am J Respir Crit Care Med 2002; 165: 818-23

56 Kumazawa Y, Kawaguchi K, Takimoto H. Immunomodulating effects of flavonoids on acute and chronic inflammatory responses caused by tumor necrosis factor alpha. Curr Pharm Des 2006; 12: 4271 - 9

57 Ziyan L, Yongmei Z, Nan Z, Ning T, Baolin L. Evaluation of the anti-inflammatory activity of luteolin in experimental animal models. Planta Med 2007; 73: $221-6$

58 Zhou P, Li LP, Luo SQ Jiang HD, Zeng S. Intestinal absorption of luteolin from peanut hull extract is more efficient than that from individual pure luteolin. J Agric Food Chem 2008; 56: 296-300

59 Wittemer SM, Ploch M, Windeck T, Müller SC, Drewelow B, Derendorf H et al. Bioavailability and pharmacokinetics of caffeoylquinic acids and flavonoids after oral administration of Artichoke leaf extracts in humans. Phytomedicine 2005; 12: 28 - 38

60 Brown JE, Rice-Evans CA. Luteolin-rich artichoke extract protects low density lipoprotein from oxidation in vitro. Free Radic Res 1998; 29: 247-55

61 Boersma MG, van der Woude H, Bogaards J, Boeren S, Vervoort J, Cnubben NH et al. Regioselectivity of phase II metabolism of luteolin and quercetin by UDP-glucuronosyl transferases. Chem Res Toxicol 2002; $15: 662-70$

62 Shimoi K, Nakayama T. Glucuronidase deconjugation in inflammation. Methods Enzymol 2005; 400: 263 - 72

63 Merfort I, Heilmann J, Hagedorn-Leweke U, Lippold BC. In vivo skin penetration studies on chamomile flavones. Pharmazie 1994; 49: 509-11

64 Chavant L, Combie H, Crs J. Memorandum: new dietary ingredients. Plant Med Phytother 1975; 9: 267 - 72

65 ai LM, Cheng H, Li WP, Liu SQ Chen MX, Xu SY. Memorandum: new dietary ingredients. Acta Anhui Med Univ 1985; $20: 1$ - 3
66 Mittra B, Saha A, Chowdhury AR, Pal C, Mandal S, Mukhopadhyay Set al. Luteolin, an abundant dietary component is a potent anti-leishmanial agent that acts by inducing topoisomerase II-mediated kinetoplast DNA cleavage leading to apoptosis. Mol Med 2000; 6: 527-41

67 Czeczot H, Tudek B, Kusztelak J, Szymczyk T, Dobrowolska B, Glinkowska $G$ et al. Isolation and studies of the mutagenic activity in the Ames test of flavonoids naturally occurring in medical herbs. Mutat Res 1990; 240: $209-16$

68 Choi JS, Park KY, Moon SH, Rhee SH, Young HS. Antimutagenic effect of plant flavonoids in the Salmonella assay system. Arch Pharm Res 1994; 17: $71-5$

69 Kawanishi S, Oikawa S, Murata M. Evaluation for safety of antioxidant chemopreventive agents. Antioxid Redox Signal 2005; 7: 1728 - 39

70 Middleton E Jr, Kandaswami C, Theoharides TC. The effects of plant flavonoids on mammalian cells: implications for inflammation, heart disease, and cancer. Pharmacol Rev 2000; 52: 673-751

71 Knekt P, Jarvinen R, Reunanen A, Maatela J. Flavonoid intake and coronary mortality in Finland: a cohort study. BMJ 1996; $312: 478-81$

72 Knekt P, Isotupa S, Rissanen H, Heliövaara M, Järvinen R, Häkkinen S et al. Quercetin intake and the incidence of cerebrovascular disease. Eur J Clin Nutr 2000; 54: 415 - 7

73 Marniemi J, Alanen E, Impivaara O, Seppänen R, Hakala P, Rajala T et al. Dietary and serum vitamins and minerals as predictors of myocardial infarction and stroke in elderly subjects. Nutr Metab Cardiovasc Dis 2005; 15: 188 - 97

74 Mink PJ, Scrafford CG, Barraj LM, Harnack L, Hong CP, Nettleton JA et al. Flavonoid intake and cardiovascular disease mortality: a prospective study in postmenopausal women. Am J Clin Nutr 2007; 85: 895 - 909

75 Yochum L, Kushi LH, Meyer K, Folsom AR. Dietary flavonoid intake and risk of cardiovascular disease in postmenopausal women. Am J Epidemiol 1999; 149: 943 - 9

76 Sesso HD, Gaziano JM, Liu S, Buring JE. Flavonoid intake and the risk of cardiovascular disease in women. Am J Clin Nutr 2003; 77: 1400-8

77 Tavani A, Spertini L, Bosetti C, Parpinel M, Gnagnarella P, Bravi F et al. Intake of specific flavonoids and risk of acute myocardial infarction in Italy. Public Health Nutr 2006; 9: 369-74

78 Quintiery L, Palatini P, Nassi A, Ruzza P, Floreani M. Flavonoids diosmetin and luteolin inhibit midazolam metabolism by human liver microsomes and recombinant CYP 3A4 and CYP 3A5 enzymes. Biochem Pharmacol 2008; 75: 1426-37

79 Wang $X$, Wang $Q$ Morris ME. Pharmacokinetic interaction between the flavonoid luteolin and gamma-hydroxybutyrate in rats: potential involvement of monocarboxylate transporters. AAPS J 2008; 10: 47 55

80 Ahlenstiel T, Burkhardt G, Köhler H, Kuhlmann MK. Improved cold preservation of kidney tubular cells by means of adding bioflavonoids to organ preservation solutions. Transplantation 2006; 81: 231 -9

81 Chen CY, Peng WH, Tsai KD, Hsu SL. Luteolin suppresses inflammationassociated gene expression by blocking NF-kappaB and AP-1 activation pathway in mouse alveolar macrophages. Life Sci 2007; 81: $1602-14$

82 Gutiérrez-Venegas G, Kawasaki-Cárdenas P, Arroyo-Cruz SR, MaldonadoFrías $S$. Luteolin inhibits lipopolysaccharide actions on human gingival fibroblasts. Eur J Pharmacol 2006; 541: 95-105

83 Hirano T, Higa S, Arimitsu J, Naka T, Ogata A, Shima Y et al. Luteolin, a flavonoid, inhibits AP-1 activation by basophils. Biochem Biophys Res Commun 2006; 340: 1 -7

$84 \mathrm{Hu}$ C, Kitts DD. Luteolin and luteolin 7-O-glucoside from dandelion flower suppress iNOS and COX-2 in RAW264.7 cells. Mol Cell Biochem 2004; 265: 107-13

85 Kim SH, Shin KJ, Kim D, Kim YH, Han MS, Lee TG et al. Luteolin inhibits the nuclear factor-kappa B transcriptional activity in Rat-1 fibroblasts. Biochem Pharmacol 2003; 66: 955-63

86 Lu HW, Sugahara K, Sagara Y, Masuoka N, Asaka Y, Manabe M et al. Effect of three flavonoids, 5,7,3', $4^{\prime}$-tetrahydroxy-3-methoxy flavone, luteolin, and quercetin, on the stimulus-induced superoxide generation and tyrosyl phosphorylation of proteins in human neutrophil. Arch Biochem Biophys 2001; 393: 73-7

87 Odontuya G, Hoult JR, Houghton PJ. Structure-activity relationship for anti-inflammatory effect of luteolin and its derived glycosides. Phytother Res 2005; 19: $782-6$

88 Park BY, Min BS, Oh SR, Kim JH, Bae KH, Lee HK. Isolation of flavonoids, a biscoumarin and an amide from the flower buds of Daphne genkwa and the evaluation of their anti-complement activity. Phytother Res 2006; 20: $610-3$ 
89 Pieroni A, Heimler D, Pieters L, van Poel B, Vlietinck AJ. In vitro anticomplementary activity of flavonoids from olive (Olea europaea L.) leaves. Pharmazie 1996; 51: 765 -8

90 Pieroni A, Pachaly P, Huang Y, Van Poel B, Vlietinck AJ. Studies on anticomplementary activity of extracts and isolated flavones from Ligustrum vulgare and Phillyrea latifolia leaves (Oleaceae). J Ethnopharmacol 2000; 70: 213-7

91 Sharma V, Mishra M, Ghosh S, Tewari R, Basu A, Seth P et al. Modulation of interleukin-1 beta mediated inflammatory response in human as- trocytes by flavonoids: implications in neuroprotection. Brain Res Bull 2007; 73: 55-63

92 Theoharides TC, Kempuraj D, Iliopoulou BP. Mast cells, T cells, and inhibition by luteolin: implications for the pathogenesis and treatment of multiple sclerosis. Adv Exp Med Biol 2007; 601: 423-30

93 Ueda H, Yamazaki C, Yamazaki M. A hydroxyl group of flavonoids affects oral anti-inflammatory activity and inhibition of systemic tumor necrosis factor-alpha production. Biosci Biotechnol Biochem 2004; 68: $119-25$ 